\title{
SOBRE(VIVÊNCIA) DA VIOLÊNCIA: OS RASTROS SILENCIADOS DA DITADURA CIVIL-MILITAR BRASILEIRA
}

\author{
Survival of Violence: The Silenced Traces of the Brazilian Civil-Military Dictatorship
}

Súper(vivencia) de la Violencia: Las Huellas Silenciadas de la Dictadura Civil-Militar Brasileña

Sur(Vie) de la Violence: Des Silencieux Traces de la Dictature Civile-Militaire Brésilienne

DOI: $10.5020 / 23590777 . r s . v 18$ iE. 6442

Gabriela Weber Itaquy (Lattes)
Mestre em Psicologia Social e Institucional pela Universidade Federal do Rio Grande do Sul.

Edson Luiz André de Sousa (Lattes)

Professor Titular da Universidade Federal do Rio Grande do Sul (UFRGS).

\section{Resumo}

A violência de Estado exercida ao longo do período da ditadura civil-militar brasileira deixou como consequência inúmeras marcas e não ditos sociais, além da produção de um trauma individual àqueles que sofreram diretamente com a violência imposta e com o desaparecimento dos seus familiares. Nessa via, ao adentrarmos no campo do traumático, tornou-se essencial aproximarmo-nos da história e do passado, sem ceder ao silenciamento imposto. Dessa forma, no referido artigo, buscou-se abrir espaços para demarcar o que não quer ser visto, ou lembrado, em uma sociedade, visando à apresentação de uma contra-história da ditadura civil-militar brasileira imersa em questionamentos e reflexões que permitam o vislumbrar de outro lugar, cercado de ressignificações, as vidas que foram silenciadas, torturadas, mortas e desaparecidas e, consequentemente, a sociedade brasileira. Diante desses objetivos, buscou-se como fio condutor de nossa reflexão o campo dos estudos utópicos na medida em que este propõe um método de leitura crítica da história, apontando seus mecanismos de repetição e, ao mesmo tempo, abrindo espaço para outras narrativas possíveis e que indicam um desejo de transposição. Dessa forma, visou-se identificar as contradições existentes no âmbito social, circunscrevendo assim um lugar de crise. Assim, nos aproximamos, nesse ponto, da proposta de Walter Benjamin de ler a história a contrapelo. Nessa via, retomaram-se os aspectos históricos da ditadura civil-militar, as violências, o campo do traumático e suas possíveis formas de transmissão. Em seguida, iniciou-se o processo de análise dos inúmeros não ditos sociais perpetrados no período ditatorial através da valorização da memória, dos restos e dos rastros. Em vias de conclusão, evidenciou-se as dificuldades da sociedade brasileira em se ocupar com o traumático imposto pelas violências exercidas na ditadura e as suas consequências na democracia e, assim, apontou-se a criação e a atuação da Comissão Nacional da Verdade como uma tentativa de inscrição de uma contra-história que valorize a narrativa e o testemunho daqueles que foram silenciados pelo traumático.

Palavras-chave: ditadura civil-militar; violência; transmissão; traumático; Comissão Nacional da Verdade.

\section{Abstract}

The violence of the State during the period of the Brazilian civil-military dictatorship left as a consequence innumerable marks and not social sayings, besides the production of an individual trauma to those who suffered directly with the imposed violence and with the disappearance of their relatives. In this way, as we entered the field of the traumatic, it became essential to approach history and the past, without yielding to the silencing imposed. Thus, in this article, we sought to open spaces to demarcate what does not want to be seen or remembered in a society, aiming at presenting a counter-history of the Brazilian civil-military dictatorship immersed in questions and reflections that allow to glimpse from another place, surrounded by resignifications, the lives that were silenced, tortured, died and disappeared and, consequently, Brazilian society. In view of these objectives, the field of utopian studies was sought as the guiding thread of our reflection insofar as it 
proposes a method of critical reading of history, pointing out its mechanisms of repetition and, at the same time, opening space for other possible narratives and which indicate a desire for transposition. In this way, the aim was to identify the contradictions existing in the social sphere, thus circumscribing a place of crisis. Thus, we approach, at this point, the proposal of Walter Benjamin to read history against the grain. In this way, the historical aspects of the civil-military dictatorship, the violence, the traumatic field and its possible forms of transmission were resumed. Then the process of analysis of the numerous social non-sayings perpetrated in the dictatorial period through the valorization of memory, remains and traces began. The Brazilian society's difficulties in dealing with the traumatic violence imposed on the dictatorship and its consequences on democracy were highlighted, and the creation of the National Truth Commission was pointed out as an attempt to inscribe a counter-history that values the narrative and testimony of those who have been silenced by the traumatic.

Keywords: civil-military dictatorship; violence; streaming; traumatic; National Truth Commission.

\section{Resumen}

La violencia del Estado ejercida a lo largo del periodo de la dictadura civil-militar brasileña dejó como consecuencia incontables marcas y secretos sociales, además del trauma individual provocado en aquellos que sufrieron directamente con la violencia impuesta y con el desaparecimiento de sus familiares. En esa vía, al adentrarnos en el campo del traumático, se hizo necesario acercarnos a la historia y al pasado, sin dar paso al silenciamiento impuesto. Así, en este artículo, se buscó abrir espacios para demarcar lo que no se quiere ser visto, o recordado, en una sociedad, objetivando la presentación de una contra-historia de la dictadura civil-militar brasileña inmersa en cuestionamientos y reflexiones que permitan el vislumbre de otro lugar, cercado de resignificaciones, las vidas que fueron calladas, torturadas, muertas y desaparecidas y, consecuentemente, la sociedad brasileña. Ante estos objetivos, se buscó como hilo conductor de nuestra reflexión el campo de los estudios utópicos al paso en que este propone un método de lectura crítica de la historia, apuntando sus mecanismos de repetición y, al mismo tiempo, abriendo espacio para otras narrativas posibles y que indican un deseo de transposición. De esa forma, se objetivó identificar las contradicciones existentes en el ámbito social, limitando así un lugar de crisis. Nos acercamos, en este punto, de la propuesta de Walter Benjamin de leer la historia a contrapelo. En esta vía se retomaron los aspectos históricos de la dictadura civil-militar, las violencias, el campo del traumático y sus posibles formas de transmisión. En seguida, se inició el proceso de análisis de los incontables secretos sociales perpetrados en el periodo dictatorial por medio de la valorización de la memoria, de los restos y de las huellas. En conclusión, se evidenció las dificultades de la sociedad brasileña en ocuparse con el traumático impuesto por las violencias ejercidas en la dictadura y sus consecuencias en la democracia y, así, se indicó la creación de la Comisión Nacional de la verdad como un intento de inscripción de una contra-historia que valorice la narrativa y el testimonio de aquellos que fueron calados por el traumático.

Palabras clave: dictadura civil-militar; violencia; transmisión; traumático; Comisión Nacional de la Verdad.

\section{Résumé}

La violence d'État exercée pendant la période de la dictature civile-militaire brésilienne a laissé conséquence de nombreuses marques sociales, ainsi que la production d' un traumatisme chez ceux qui ont souffert directement avec la violence imposée à eux et avec le disparition de leurs familles. Dans ce sens, quand on rentre dans le domaine des traumatismes, c'est indispensable d'aborder l'histoire et le passé, sans céder au silence forcé. De cette façon, dans cet article, on a cherché à ouvrir des espaces pour délimiter ce qui ne veut pas être vu, ou rappelé, dans une société, visant à la présentation d'une contre-histoire de la dictature civil-militaire brésilienne immergée dans les questions et réflexions qui permettent apercevoir chez d'autre endroit, entouré de signification, les vies qui ont été réduites au silence, torturées, tuées et disparues et, par conséquence, la propre société brésilienne. Devant ces objectifs, on a cherché comme fil conducteur de notre réflexion, le domaine d'études utopiques à mesure où il propose une méthode de lecture critique de l'histoire, et montre ses mécanismes de répétition et, en même temps, donne place aux autres récits possibles et indiquent un désir de transposition. De cette façon, on a cherché à identifier les contradictions existantes dans la sphère sociale, circonscrivant ainsi un lieu de crise. Donc, on s'approche, à ce point, de la proposition de Walter Benjamin de lire l'histoire à contre-courant. En ce sens, on a reprit les aspects historiques de la dictature civil-militaire, de la violence, du champ traumatique et leurs formes possibles de transmission. Ensuite, on a commencé le processus d'analyse de nombreux non-dits sociaux commis dans la période dictatoriale par la récupération de la mémoire, des restes et des traces. Comme conclusion, des difficultés de la société brésilienne en ce qui concerne la violence traumatique imposée par la dictature et ses conséquences dans la démocratie ont été soulignées. Ainsi, on a attiré l'attention au travail de la Commission Nationale de Vérité comme un essai d'une contre-histoire qui souligne le récit et le témoignage de ceux qui ont été réduits au silence par le traumatisme.

Mots-clés: dictature civil-militaire; violence; transmission; traumatique; Commission Nationale de la Vérité. 
Atualmente a sociedade brasileira passa por inúmeros conflitos e crises no campo social, político e econômico. A população tem utilizado movimentos sociais, protestos e reivindicações como maneiras de demonstrar sua insatisfação. Um exercício democrático interessante, porém ressalva-se a preocupação com o pedido de intervenção militar realizado por uma parcela representativa. Inúmeros cartazes foram levados às manifestações referindo-se à ditadura como única solução para as grandes dificuldades enfrentadas no país.

O chamado feito pelo retorno do totalitarismo demarca a invisibilidade da história brasileira e a desvalorização da memória daqueles que foram torturados, mortos e desaparecidos durante a luta pela democracia no período ditatorial. Dessa forma, acredita-se que, como modo de resistir ao imperativo imposto pelo não dito social, resta à população não ceder a tal silenciamento.

Nessa via, propõe-se adentrar no campo do traumático imposto pelas violações exercidas no período ditatorial como modo essencial de aproximação do presente à história e, consequentemente, ao passado. Parte-se de modo conjunto com a perspectiva utópica enquanto uma possibilidade de método que demonstra uma insatisfação diante do presente; marcando, principalmente, um desejo de transposição (Sousa, 2007).

Ressalta-se que, enquanto método, a utopia não visa alcançar objetivos e aspirações, mas sim, primeiramente, desfamiliarizar o que é familiar, facilitando o encontro com as contradições e continuidades existentes no âmbito social e circunscrevendo um lugar de crise (Moylan \& Baccolini, 2007).

Deve-se ressaltar que a utopia não busca imaginar um futuro melhor, mas mostrar nossa incapacidade de imaginar tal futuro.

(...) a vocação da utopia é o fracasso, o seu valor epistemológico está nas paredes que ela nos permite perceber em torno de nossas mentes, nos limites invisíveis que nos permite detectar por mera indução, no atoleiro das nossas imaginações no modo de produção. Concluímos, portanto, que a utopia mostra aquilo que não podemos imaginar. Só que não o faz pela imaginação concreta, mas sim por meio dos buracos no texto (Jameson, 1997, p. 85).

Lacan posiciona o pensamento da utopia enquanto um lugar de lugar nenhum, sendo por meio dela que o pensamento poderá ser livre para buscar uma reforma possível na norma (Lacan, 2008). Acredita-se na busca de uma visão desatrelada da norma através da lógica do contrafluxo, abrindo espaços para demarcar o que não quer ser visto, ou lembrado, em uma sociedade.

O viés utópico permite o atravessamento da "obscuridade do instante vivido", ultrapassando o curso natural dos acontecimentos (Bloch, 2005, p. 23) para depois possibilitar a revisitação ao passado, mas quebrando com a eterna repetição. Parafraseando Bloch, deve-se substituir o bafo impregnado de mesmice vindo do porão, pelo ar puro e renovador da manhã. Assim, busca-se a perturbação da ordem dos acontecimentos, possibilitando novas leituras e significações de mundo.

Desse modo, propõe-se a reflexão a partir do campo dos estudos utópicos na medida em que propõe um método de leitura crítica da história, apontando seus mecanismos de repetição e, ao mesmo tempo, abrindo espaço para outras narrativas possíveis que indicam um desejo de transposição. Dessa forma, visa-se identificar as contradições existentes no âmbito social, circunscrevendo um lugar de crise. Assim, aproximando-se da proposta de Walter Benjamin de ler a história a contrapelo, abrindo espaço para uma contra-história da ditadura civil-militar brasileira que permita o vislumbrar de outro lugar, cercado de ressignificações, a sociedade brasileira e, principalmente, as vidas daqueles que foram silenciados, torturados, mortos e desaparecidos.

\section{Em Busca dos Rastros dos Tempos Ditatoriais}

A ditadura civil-militar brasileira foi instaurada em 1964, através do golpe de Estado ordenado pelo Exército, e se estendeu até o ano de 1985. No período que antecedeu essa instauração, o país vivia momentos de grande instabilidade política, tendo em vista que, nos anos entre 1946 e 1964, existia uma "democracia frágil, instável e hesitante". Esses anos carregavam o peso de uma polícia política gestada no período do Estado Novo, em que havia a crença de quem possuía poder podia tudo através das práticas violentas. No ano de 1961, Jânio Quadros havia sido eleito, porém renunciou após um ano, sendo empossado o vice, João Goulart, que não possuía o apoio dos militares e de parte da sociedade civil. Os longos 21 anos ditatoriais foram marcados por diversas mudanças políticas, econômicas, sociais e culturais, bem como pela intensa repressão político-social aos seus opositores. Nesse período, o Sistema Judiciário e o Legislativo foram dominados pelo regime militar (Brasil, 2014a).

A imprensa passou a ser controlada e as notícias monitoradas por agentes estatais. A livre manifestação foi calada, os sindicatos invadidos, os locais de ensino reprimidos e o povo perdeu sua liberdade de expressão. Muitos empresários, setores conservadores da Igreja e veículos de comunicação, foram apoiadores e beneficiários da ditadura. Assim, devemos dizer que parte da sociedade civil apoiou o golpe. Por esse motivo e pelo fato de ter havido um movimento de resistência à ditadura, acredita-se que a melhor nomenclatura usada para referenciar esse período seja "ditadura civil-militar" (Brasil, 2014a, 2014b, 2014c; Tavares, 2005; Ventura, 1988). 
Na primeira página do Jornal do Brasil publicado no dia seguinte à promulgação do AI-5, em 1968, já se notava as dificuldades que a ditadura havia instaurado e os mais severos cerceamentos dos direitos que estavam por vir. Assim anunciaram: "Tempo negro. Temperatura sufocante. O ar é irrespirável. O país está sendo varrido por fortes ventos" (Ventura, 1988, PP. 288-289). Tais frases somente puderam ser ditas em entrelinhas, pois os agentes militares, naquele momento. haviam tomado a redação de todo o país e a censura havia ganhado grandes proporções.

Os militares apoderaram-se do exercício de decidir sobre a vida ou a morte das pessoas. Os porões da ditadura foram marcados por inúmeras formas de violência e torturas que visavam o apagamento subjetivo, além do grande número de prisões indevidas, exílios, cassações, demissões, mortes e desaparecimentos dos considerados "comunistas", "subversivos", e de seus familiares (Brasil, 2014a).

Conforme Safatle e Teles (2010):

No cerne de todo totalitarismo, haverá sempre a operação sistemática de retirar o nome daquele que a mim se opõe, de transformá-lo em um inominável cuja voz, cuja demanda encarnada em sua voz não será mais objeto de referência alguma. Este inominável pode, inclusive, receber, não um nome, mas uma espécie de designação impronunciável que visa isolá-lo em um isolamento sem retorno. "Subversivo", "terrorista" (p. 238).

Tais sujeitos passaram a ser considerados inimigos do Estado devido ao fato de lutarem por diferentes verdades e ideais dos que eram impostos pela ditadura. Muitas vidas tiveram que enfrentar experiências traumáticas, pois foram violentadas e silenciadas pelo Estado, aquele que possui o papel de proteção e garantia dos direitos, mas que exerceu, e ainda exerce, em muitos casos, a violação.

Desse modo, percebe-se que a ditadura civil-militar glorificou a herança da violência e os piores modos de dominação que foram produzidos na nossa história brasileira. No Brasil, conforme o Relatório sobre Tortura e Direitos Humanos, em 2000, a prática de torturas e tratamentos desumanos, degradantes e cruéis foi exercida desde a colonização portuguesa. A colonização e a escravidão de negros e índios impuseram, por meio da violência constantemente aplicada, uma dessocialização e despersonalização. Tais atrocidades deixaram uma profunda marca em nossa história, perpetuando-se como o que não deve ser lembrado. O Relatório anuncia que as violências foram propulsoras do comportamento dos torturadores do DOICodi (Destacamento de Operações de Informações - Centro de Operações de Defesa Interna) e de outros centros de tortura existentes na ditadura civil-militar (Arantes, 2009b).

Torna-se relevante o repensar sobre o codinome exaustivamente aplicado aos inimigos da época ditatorial - os subversivos - tensionando o significado da palavra. Nesse período, a palavra era facilmente associada aos ditos comunistas e terroristas, além de estar constantemente relacionada aos partidos de oposição que existiam na clandestinidade devido à repressão. Ressalta-se que o referido termo já era utilizado em demais períodos históricos do país, tal como o Estado Novo. Conforme o dicionário Aurélio, os subversivos são aqueles que pretendem perturbar ou alterar a ordem estabelecida, contrariando as ideias ou opiniões da maioria (Ferreira, 2010). A palavra subversão também é marcada pelo ato ou efeito de subverter, voltar de baixo para cima, revolver, perverter, arruinar, destruir e submergir.

Diante dessa proposta de subversão, torna-se importante a rememoração de alguns artistas que, através de suas obras, incidiram no social e desvendaram alguns véus encobridores da violência de Estado. Assim, tensionaram o tipo de arte que poderia ser relevante diante de circunstâncias repressivas e propiciaram que ela fosse um instrumento político e de resistência.

O artista Artur Barrio, em 1970, realizou uma intervenção urbana com o seu trabalho 'trouxas ensanguentadas', como uma forma de criticar a repressão política, expondo as violências, torturas e mortes praticadas pelo Estado ditatorial. O artista comprou vinte quilos de carne bovina e ossos e os colocou dentro de 14 trouxas, amarradas com uma corda e manchadas de sangue. As trouxas foram deixadas anonimamente às margens de rios e esgotos da cidade de Belo Horizonte/MG. Barrio buscava que os espectadores confundissem as trouxas com corpos humanos, mostrando a vulnerabilidade de toda a sociedade aos atos do regime ditatorial. Acredita-se que cinco mil pessoas tenham visto as trouxas em um domingo no Parque Municipal, fato que trouxe a participação da polícia e dos bombeiros. Os agentes públicos destruíram as trouxas e enviaram os ossos para análise (Calirman, 2013).

Ainda no mesmo ano, Cildo Meireles teve a ideia de criar um sistema de contrainformação que não pudesse ser manipulado ou controlado pela ditadura, opondo-se às informações da imprensa, rádio e televisão. Assim, as 'Inserções em Circuitos Ideológicos' nasceram com dois projetos. No projeto Coca-Cola, o artista gravou nas garrafas retornáveis do produto informações e opiniões críticas referentes à opressão e à violência militar, depois as devolveu à circulação. As mensagens ficavam quase invisíveis quando a garrafa estava vazia, mas, quando cheia com o líquido escuro, tornavam-se legíveis. O artista interviu em mais de mil garrafas. No projeto Cédula, notas de cruzeiros ou dólares eram carimbadas com frases que criticavam a situação política do país. Dentre os dizeres do artista estava a pergunta: 'Quem matou Herzog?'. Assim, Meireles colocou dentro do circuito social imagens, ideias e informações que pairavam sobre o campo obscuro daquilo que não deveria ser dito, demarcando falhas no sistema que puderam ser usadas como forma de resistência e crítica (Calirman, 2013). 


\section{O Traumático e suas Formas de Transmissão}

A violência propicia a capacidade de paralisar as diferentes formas de vida, deixando muitos mudos e estáticos, e jogando suas vítimas no 'completo desamparo'. Assim, em muitos momentos, não sabem o que dizer, pensar ou imaginar, restando um silêncio inquietante que anuncia a ferocidade do trauma (Sousa \& Tessler, 2004).

Dessa forma, a experiência de violência demarca o traumático e o irrepresentável. Um lugar em que a linguagem, a possibilitadora do reconhecimento da diferença, fracassa, pois foi sobreposta por uma ação absoluta e radical instaurada pela violência (Endo, 2005). A pulsão de destruição é extrema e objetiva aniquilar o tempo psíquico. Após sua devastação, resta apenas aquilo que conseguiu sobreviver às torturas, aos desaparecimentos forçados, os corpos batidos e violentados (Endo, 2011).

Diante da situação de violência e tortura imposta pelo Estado, o sujeito passa a ter o seu direito de morte retirado, restando uma impotência. Nessa via, já não existe mais o poder de escolha entre a vida ou a morte, surgindo apenas uma experiência inominável e a busca incessante de nomear minimamente o traumático. Acredita-se que aquilo que é vivido numa dimensão catastrófica, ou terrorífica, amedronta e horroriza tanto quanto envergonha (Endo, 2005). Gagnebin (2000, p.106) pontua que " (...) o horror enxergado não é somente tão inesquecível quanto irrepresentável (...) ele possui uma estranha força de contaminação, que suja e marca de vergonha os olhos que o viram".

Conforme Benjamin, a experiência geralmente enraíza-se sobre o corpo na busca de reconhecimento, porém, diante das experiências terrificantes, pode haver um esvaziamento de tal dimensão. Rastros na construção identificatória do sujeito são deixados para trás, ocorrendo um empobrecimento do valor da experiência e de sua transmissão (Benjamin, 1933/1985a).

A experiência de choque deflagra a impossibilidade da linguagem e das narrativas assimilarem o acontecimento, pois o trauma separa o sujeito do acesso ao simbólico, negando a capacidade de dominá-lo e elaborá-lo psiquicamente. O traumatismo se impõe como uma temporalidade de ruptura que invade e marca temporalmente um instante, mas que não é fácil de ser esquecido, perpetuando o silenciamento e o amordaçamento da palavra (Soler, 2004). Aos sobreviventes, o trauma aparece carregado de angústia e culpa. Ocorre, então, a perda da transmissão que era ponte entre passado e presente, havendo um rompimento com o passado. No Brasil, a ditadura impôs tal quebra entre o passado e o presente por meio do emudecimento instaurado pelo traumático.

No texto "Sobre o conceito da história", Benjamin (1940/1985c, p. 224) pontua: “Articular historicamente o passado não significa conhecê-lo 'como ele de fato foi'. Significa apropriar-se de uma reminiscência, tal como ela relampeja no momento de um de perigo". Apesar das dificuldades, devemos articular o passado e não descrevê-lo como se descreve um objeto. Nesse sentido, não podemos dizer tudo, devemos ir à busca dos rastros e partir contra a ideia de uma verdade indiscutível e exaustiva.

O rastro inscreve a lembrança de uma presença que não existe mais e que sempre corre o risco de se apagar definitivamente. Sua fragilidade essencial e intrínseca contraria assim o desejo de plenitude, de presença e de substancialidade que caracteriza a metafísica clássica (Gagnebin, 2006, p. 44).

Gagnebin (2006) reaviva em nós a persistente vontade dos nazistas de acabar com os rastros das atrocidades realizadas, matando e desaparecendo com os corpos, assim, negando a existência do assassinato e anulando a credibilidade dos sobreviventes. Acreditavam na impossibilidade de uma história a ser contada sobre os campos de concentração. Podemos dizer que a ditadura brasileira seguiu tal estratégia nazista ao sumir com os arquivos, matar e desaparecer com os corpos. Dessa forma, apagou os rastros e delegou o silenciamento.

Primo Levi (1988) pontua que o pesadelo comum que assombrava os prisioneiros no campo de concentração era o fato de retornarem às suas casas e, ao contarem os sofrimentos que passaram aos seus entes queridos, eles levantariam e sairiam do ambiente do diálogo, sem querer escutar e crer no ocorrido.

Nessa via, precisa-se transmitir o inenarrável e manter viva a memória dos sem-nome, daqueles que foram mortos e tiveram seus corpos desaparecidos lutando contra o esquecimento e a repetição do horror. Desse modo, a verdade do passado passa a ser completa com a exigência de um presente verdadeiro (Gagnebin, 2006).

Diante das ruínas e dos restos de uma tradição espedaçada, o narrador deve mostrar alguma narração possível para que o passado não caia no esquecimento. Acredita-se que os elementos que sobram no discurso são os que demarcam o sofrimento, e aqueles que sem rastros acabam sendo apagados da memória (Benjamin, 1936/1985b).

Conforme Blanchot (1987), a narrativa não é vista enquanto ato de relatar o acontecido, e sim a aproximação do próprio acontecimento, do lugar em que o sujeito é chamado a produzir, incluindo o que ainda está por vir. Desse modo, a narrativa é um movimento em direção a um ponto não só desconhecido como ignorado e estranho, que, no primeiro momento, parece não existir.

Assim, o ato narrativo requer intensidade e impossibilidade, pois trata de um espaço que se abre "à dispersão, à fissura em que o exterior é a intrusão que sufoca, é a nudez, é o frio daquilo em que se permanece descoberto" (Blanchot, 1987, p.22). Dessa maneira, a experiência em si e a experiência da narrativa (atualizadora da experiência em si) podem deslocar o sujeito 
e promover a abertura para o deslocamento da ordem dos acontecimentos, propiciando um passo a favor da historicização.

A figura daquele que narra também pode ser exemplificada pela figura do trapeiro, do catador de sucata e lixo. Essa pessoa que recolhe os restos, os cacos, os detritos, situação configurada pela pobreza, mas também pelo desejo de que nada se perca. O narrador sucateiro recolhe aquilo que é deixado de lado, o que não parece não ter mais sentido e importância, tudo aquilo que a história oficial não soube o que fazer. Nesse sentido, o narrador tem essa função de transmitir aquilo que a tradição não recorda, aquilo que é inenarrável, sendo fiel ao passado e aos mortos mesmo sem saber quem eles são (Benjamin, 1936/1985b).

Ao juntar os restos e os rastros que sobram da vida e da história oficial, há uma tarefa de protesto, mas também do verdadeiro narrador autêntico, ou seja, aquele que viaja no tempo e transmite o conhecimento do passado, ou do lugar distante, sem que a separação espacial ou temporal seja um empecilho ( Benjamin, 1940/1985c).

Diante da existência da narração e da transmissão do traumático, entra em questão a importância da memória. A rememoração visa, em vez da repetição do que se lembra, a abertura de buracos ao esquecido e recalcado, marcando aquilo que não teve direito à lembrança e a palavras. Desse modo, demarca-se uma atenção precisa ao presente e as ressurgências nele do passado. Ressalta-se que a memória vive constantemente a tensão entre a presença do presente, a lembrança do passado desaparecido e a insurgência que invade o presente (Costa, 2011).

A memória deve ser percebida enquanto dependente das condições de transmissão, sem ser equivalente ao fato acontecido, mas apoiando-se nele. Há uma enorme riqueza e fragilidade na memória, conforme Ana Costa (2011, p. 29): “A memória não é conteúdo, ela traz a repetição do pior, do resto que ficou não resolvido, que implica a face do que não se quer, nem na vida pessoal, nem nas construções sociais, mas que não impede a repetição".

Ante essa repetição do terrorífico, Adorno (1995) pontua a nossa tendência e vontade em entregarmo-nos à amnésia, seja através dos modos de não querermos saber, seja por meio do fazermos de conta que não sabemos - denegações, recalques, e também por meio dos mecanismos da memória, do esquecimento e da repetição. Assim, devemos combater o desejo de esquecimento e notar as diferentes maneiras pela qual o passado é tornado presente, se permanece recriminado, ou se resiste ao horror por meio da tentativa de compreender o incompreensível.

Gagnebin (2006, p. 97) pontua o nosso dever em "preservar a memória, em salvar o desaparecido, o passado, em resgatar, como se diz, tradições, vidas, falas e imagens". Desse modo, cremos na memória enquanto um processo seletivo embebido em afetos e que demarca a razão em acreditarmos que a lembrança relatada poderá ser ressignificada, pois sua rememoração e repetição poderão ir desfazendo a dor de uma experiência-limite (Arantes, 2008).

Diante do horror do traumático, aquilo que é inimaginável deve ser imaginado, apesar de tudo, para que possa representar alguma coisa, nem que seja o mínimo do que é possível saber. Olhar o mundo através de um ponto de vista arqueológico é comparar o que vemos no presente àquilo que sobreviveu e o que sabemos ter desaparecido no tempo (Didi-Huberman, 2013).

Conforme Benjamin (1932/1987a), aquele que busca se reaproximar do passado soterrado deve comportar-se como um homem que escava sem temor de voltar ao mesmo fato, e espalhar como se espalha a terra e revolver como se revolve o solo. Didi-Huberman (2013) aponta que, em Auschwitz, antigo campo de concentração nazista, a própria terra regurgita os vestígios das chacinas realizadas. Em períodos de inundações, ocasionadas pela chuva, lascas e fragmentos de ossos das vítimas voltavam à superfície. Fato que fez com que os responsáveis pelo sítio sentissem a obrigação de aterrá-lo para tentar soterrar o que insiste em aparecer.

No texto Imagens do Pensamento, Benjamin faz uma comparação entre a atividade do lembrar e a escavação arqueológica, analisando a memória como um modo de escavação. Quando escavamos, achamos restos, ruínas e vestígios nos solos. Por meio deles, reconstruímos o passado, mas não exatamente como foi. Assim, tal técnica não surge como um modo de explorar o passado, e sim de entendermos o presente (Benjamin, 1987b).

Sendo assim, a memória não pode mais ser vista enquanto um lembrar interiorizado e totalizador, ou uma verdade absoluta catalogada, e sim como uma interrupção do tempo, marcando aquilo do passado que salta para o presente, uma forma de rememoração e comemoração. Portanto, a arte da memória não se restringe àquilo que é facilmente visível.

Desse modo, a memória se torna um dever, tendo em vista que ela necessita fazer parte da história, pois somente existirá o esboço de um futuro diferente se os sujeitos conseguirem não virar as costas para as suas histórias pessoais e sociais. Benjamin (1940/1985c) pontua esse impasse sobre memória e esquecimento em seu ensaio "Sobre o conceito da história".

O anjo da história deve ter esse aspecto. Seu rosto está dirigido para o passado. Onde nós vemos uma cadeia de acontecimentos, ele vê uma catástrofe única, que acumula incansavelmente ruína sobre ruína e as dispersa a nossos pés. Ele gostaria de deter-se para acordar os mortos e juntar os fragmentos. Mas uma tempestade sopra do paraíso e prende-se em suas asas com tanta força que ele não pode mais fechá-las. Essa tempestade o impele irresistivelmente para o futuro, ao qual ele vira as costas, enquanto o amontoado de ruínas cresce até o céu. Essa tempestade é o que chamamos progresso (Benjamin, 1940/1985c, p. 226).

Deve-se desconfiar e duvidar da cultura dos vitoriosos e da história oficial. Benjamin (1940/1985c) propõe a escrita de 
uma contra-história que exponha a catástrofe de acontecimentos da história oficial e mostre o que não foi dito, demonstrando as lacunas e recuperando a tradição dos vencidos e oprimidos. Não se trata de apagar os rastros, e sim de reescrevê-los.

Diante dessa possibilidade de reinscrição, acredita-se na importância da sociedade brasileira deparar-se com o passado e resgatar os seus rastros e restos, prezando, principalmente, pela narrativa e testemunho daqueles que sobreviveram à passagem do traumático.

\section{O Mal-estar Social e o Regurgitar dos Restos da História}

Como é difícil acordar calado.../Se na calada da noite eu me dano/ Quero lançar um grito desumano/ Que é uma maneira de ser escutado/ Esse silêncio todo me atordoa/ Atordoado eu permaneço atento/ $\mathrm{Na}$ arquibancada pra a qualquer momento/ Ver emergir o monstro da lagoa/ Pai, afasta de mim esse cálice (cale-se)/ De vinho tinto de sangue (Buarque, 1978).

A letra escrita em 1973, período ditatorial, por Chico Buarque e Gilberto Gil, foi censurada pelo regime ditatorial e só pôde ser lançada no ano de 1978. Tal escrita denuncia que a interjeição "cale-se!" era a grande proposição imposta através do apagamento da liberdade, da intensa repressão e violência que aconteciam na "calada da noite".

Cansados de tanta opressão e diante do aumento do número das pessoas que se encontravam exiladas e presas, os familiares, amigos e adeptos da democracia uniram-se em busca de anistia. A ditadura já estava enfraquecida devido às pressões políticas internacionais e ao grande movimento de resistência. Ressalta-se que o período ditatorial teve seu término apenas em 1986, porém o processo de transição política já vinha sendo articulado anos antes com a criação da Lei da Anistia.

Em 1978, antes da promulgação da Lei da Anistia, ocorrida em 28 de agosto de 1979, foram criados os Comitês Brasileiros pela Anistia, organizações independentes que reuniam pessoas dispostas a lutar pelo reestabelecimento dos direitos individuais, sociais e políticos. Porém, as reivindicações propostas pelos Comitês não foram seguidas e a Lei foi aprovada pelo voto de líderes parlamentares, que viviam sob o limite do regime ditatorial, sem ser discutida e acordada pelos diferentes setores da sociedade, desconsiderando a mobilização social existente. Assim, a Lei da Anistia não facilitou a reintegração profissional dos servidores que haviam sido punidos; não liberou todos os presos políticos, e os quartéis não receberam os militares cassados (Arantes, 2009a).

Desse modo, o regime militar desfigurou o objetivo que os Comitês davam a anistia e aproveitou para preparar a impunidade pelos crimes realizados. Interpretou a anistia enquanto "ampla, geral e irrestrita", aplicável às vítimas e aos torturadores. Assim, uniu o crime político com o crime imprescritível de tortura (Arantes, 2009a).

Naquele momento, a violência sistemática de um Estado contra um cidadão passou a valer o mesmo que a violência de um cidadão contra o Estado ilegal. Colocou-se oprimido e opressor no mesmo plano, esquecendo-se que aqueles cidadãos estavam exercendo o seu direito de dizer não ao totalitarismo, mesmo que pela luta armada.

A Lei da Anistia acabou garantindo que os praticantes de graves violações aos direitos humanos, aqueles que foram responsáveis por torturas, mortes e desaparecimentos, não respondessem legalmente por seus atos. Assim, em prol de uma dita reconciliação, vários crimes ficaram sem respostas. O Estado preferiu colocar uma pedra no assunto, negando, ocultando e distorcendo-o. Naquele momento, o mandamento era que a população virasse a página, porém tudo que é recalcado, em algum momento, retorna na forma de excessos.

As vítimas de tais violências ficaram sem ter direito à verdade, à justiça e à reparação, assim o assunto pairou no campo do que não deve ser dito, e sim esquecido. Conforme Lisboa (2004, p. 162), representante das famílias na Comissão de Mortos e Desaparecidos Políticos do Rio Grande do Sul:

A anistia conquistada trouxe ao país os presos políticos, exilados e clandestinos, mas os mortos e desaparecidos não voltaram sequer na forma de um atestado de óbito. (...) Os torturadores, mandantes e responsáveis pelas torturas e assassinatos não foram condenados, nem sequer julgados ou citados em processos criminais.

O Brasil acabou sendo o único país da América Latina que, após o término de sua ditadura, não julgou e nem puniu publicamente seus torturadores (Kehl, 2011). Na Argentina, houve um pressionamento por parte dos setores da sociedade civil, que forçaram o governo Kirchner a anular o aparato legal que impedia a punição dos torturadores da ditadura. Desse modo, a justiça não se amedrontou em abrir processos contra militares e buscar renomear os seus desaparecidos e reinscrever suas histórias. No Chile, devido à grande mobilização mundial produzida pela prisão de Augusto Pinochet em Londres, ocorreram muitas condenações dos militares, e o Exército reconheceu, por meio de notas oficiais, não se solidarizar com o seu passado, reconhecendo seus erros (Safatle \& Teles, 2010). 
No Brasil, as inúmeras pessoas que foram violentadas e torturadas, e as que sofreram com o desaparecimento de entes queridos, ainda sofrem com a radicalidade da dor e com os sintomas que o trauma propicia. Rosa (2002) acredita que o trauma é possibilitador de um tempo subjetivo, que proporciona como resposta a perpetuação da angústia, a repetição do silêncio, ou o impedimento dos processos do luto. Salienta-se que as violações perpetradas pelo Estado pouco foram reconhecidas e reparadas socialmente, impedindo a elaboração através da reconstrução de um lugar discursivo por meio da reconstrução da história e reinterpretação do passado. Ainda hoje, o Exército diante uma lógica de apagamento, nega a prática de tortura no período ditatorial. O que impede nosso país de lidar de forma mais justa com esta história?

Em 2008, o então Ministro da Justiça, Tarso Genro, e o então Secretário Nacional dos Direitos Humanos, Paulo Vannucchi, entraram com um recurso no Supremo Tribunal Federal pedindo a revisão da Lei da Anistia. Tais órgãos alegaram que a prática de tortura é crime de lesa-humanidade, não sendo passível de prescrição e de anistia. Porém, o Supremo Tribunal Federal afirmou que tal revisão poderia ocasionar desestabilidade política (Sousa, 2010).

Em 2010, o Brasil foi condenado pela Corte Interamericana de Direitos Humanos da OEA em uma ação movida por familiares de mortos e desaparecidos na Guerrilha do Araguaia (movimento armado desencadeado pelo PC do B, entre 1972 e 1974 na região de Marabá, no Pará). A decisão proferida pela Corte IDH teve o intuito de fazer com que o Brasil investigasse penalmente os fatos por meio da Justiça ordinária, alegando que "as disposições da Lei da Anistia que impedem a investigação e sanção de graves violações de direitos humanos são incompatíveis com a Convenção Americana" (Carvalhal, 2014). Assim, a Lei da Anistia não deveria ser um obstáculo para identificação e punição dos responsáveis.

A partir de tal decisão, procuradores federais iniciaram ações penais contra agentes do Estado acusados de sequestro durante os governos militares. Até hoje corpos estão desaparecidos. Os procuradores creem na continuidade de tais crimes, ou seja, o fato de eles ainda perdurarem. Nessa via, não estariam salvaguardados pela Lei da Anistia. Tais ações apresentaram alguns avanços, porém logo permaneceram estagnadas, restando dúvidas de como o Estado brasileiro lidará com as acusações.

Kehl (2010) acredita em tal situação enquanto parte do sintoma social brasileiro expresso através dos sujeitos que, individualmente ou em grupo, sofrem e manifestam os efeitos de seu sofrimento por meio de discursos e atitudes que se automatizam nas estruturas psíquicas e podem agravar-se conforme o tempo. Através dessa tomada reflexiva do passado brasileiro, podemos notar que pedaços da história foram destinados ao esquecimento e demandas de minorias foram silenciadas.

Desse modo, em 16 de maio de 2012, mais de vinte e cinco anos passados do fim da ditadura, a Comissão Nacional da Verdade (CNV) surgiu como um avanço em busca da memória, apesar das dificuldades encontradas em sua constituição. A Comissão foi instituída pela Lei 12528/2011, com a finalidade de apurar graves violações de Direitos Humanos ocorridas entre 18 de setembro de 1946 e 5 de outubro de 1988. A Comissão buscou promover o entendimento circunstanciado dos casos de torturas, mortes, desaparecimentos forçados, ocultação de cadáveres e autoria dos crimes, mesmo os ocorridos no exterior; identificar e tornar público os principais locais e instituições relacionados à prática de violação dos direitos humanos; auxiliar na localização e identificação de corpos e restos mortais de desaparecidos políticos; buscar a prevenção de violação de direitos humanos, promovendo a reconciliação nacional; reconstrução de casos de graves violações, colaborando com o oferecimento de assistência às vítimas (Brasil, 2014a).

Dentre as dificuldades encontradas na criação da Comissão estava o fato da CNV abranger a investigação de graves violações de Direitos Humanos sem especificar quem eram os violadores de tais direitos. Do mesmo modo, o período selecionado não se referia exclusivamente ao período ditatorial. Somente em setembro de 2012, a CNV, por meio da Resolução $\mathrm{n}^{\mathrm{o}}$ 2, conseguiu estabelecer de modo definitivo que as graves violações de Direitos Humanos examinadas eram as praticadas por agentes públicos, pessoas a seu serviço, com apoio ou no interesse do Estado. Ressalta-se que esse fato define o principal marco legal da CNV (Brasil, 2014a).

O Brasil foi o último país da América Latina a implantar a Comissão Nacional da Verdade, e essa somente foi estabelecida através do decreto da Corte Interamericana de Direitos Humanos em conjuntura com pressões políticas. Constata-se que, desde o ano de 1974, foram construídas 23 comissões na América Latina. A primeira foi realizada na Bolívia em 1982; na Argentina, iniciou-se com a Comissão Nacional sobre o Desaparecimento de Pessoas em 1983; no Peru, foi instaurada em

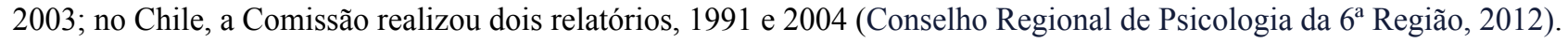

Ao instaurar a Comissão, a então presidenta Dilma Rousseff destacou a necessidade do Brasil em conhecer a totalidade de sua história, ressaltando o fato das investigações não serem movidas pelo ódio ou revanchismo. Ela pontuou que "a ignorância sobre a história não pacifica, pelo contrário, mantém latente mágoas e rancores" (Portal do Planalto, 2012). Ainda relatou:

O Brasil merece a verdade, as novas gerações merecem a verdade e, sobretudo, merecem a verdade factual aqueles que perderam amigos e parentes e que continuam sofrendo como se eles morressem de novo e sempre a cada dia. É como se disséssemos que, se existem filhos sem pais, se existem pais sem túmulo, se existem túmulos sem corpos, nunca, nunca mesm 
o, pode existir uma história sem voz. E quem dá voz à história são os homens e as mulheres livres que não têm medo de escrevê-la (Portal do Planalto, 2012, para.8).

Torna-se importante tensionarmos o conceito de verdade proposto pela Comissão Nacional da Verdade. Afinal, a verdade é sempre não-toda e depende de cada sujeito. Para que possamos manter uma verdade, precisamos constituir uma fiç̧ão compartilhada que nos mostre o quanto estamos no campo da falta. Desse modo, a verdade depende sempre da narrativa ficcional, aquela que também pode sustentar o sujeito diante das construções históricas. Assim, aquilo que fica no campo do traumático fica sem registro, instigando o sujeito em uma construção ficcional que faça laço com o social (Costa, 2011). Este, sim, torna-se um legado importante da Comissão, a busca da verdade do sujeito enquanto construção narrativa e ficcional.

A Comissão teve a duração de três anos, estendeu-se até 16 de dezembro de 2014. Seu trabalho foi embasado em várias visitas aos diferentes estados brasileiros e investigações baseadas em documentos, pesquisas e audiências públicas pautadas na escuta dos testemunhos e depoimentos das vítimas de graves violações de Direitos Humanos (Brasil, 2014a).

Ressalta-se que as Comissões da Verdade são produtos de negociações e correlações de forças políticas. No Brasil, entidades, órgãos e igrejas elaboraram muitos relatos sobre os ocorridos na época da ditadura civil-militar. Todavia, a Comissão da Verdade tem função pública e delimitada pelo poder do Estado. Assim, leva-se em consideração que cada Comissão trabalha de forma diferenciada, sem buscar fazer justiça, pois ela é formada por pessoas que visam à verdade, demarcando o testemunho, validando o assunto enquanto representantes do Estado e tornando-o conhecido pela sociedade (Oropeza, 2012).

De acordo com os dados obtidos pela Comissão Nacional da Verdade, em 1964, no primeiro ano do regime civil-militar, pelo menos 50 mil pessoas foram presas no Brasil. Estima-se que, no período ditatorial, 11 mil pessoas tenham sido acusadas em inquéritos das Auditorias Militares, sendo 5 mil condenadas, dos quais 1.792 por "crimes políticos" catalogados pela Lei de Segurança Nacional e 10 mil pessoas passaram pelos porões do DOI-Codi (Cunha, 2014).

A Comissão Nacional da Verdade surgiu como uma forma de entendermos como o Brasil foi constituído historicamente, revelando as relações de forças que funcionaram em determinado momento e as repercussões que ocasionam para a atual sociedade. Assim, conhecer o passado é essencial para reconhecer e entender as violações no presente, prevenindo repetições

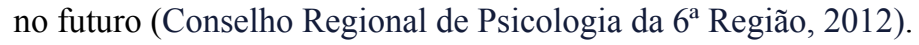

De acordo com Coimbra (2010), a reparação por parte do Estado é um direito dos cidadãos que sofreram graves violações aos direitos humanos. No Brasil, essa tem sido realizada, principalmente, através da reparação econômica, porém ela só possui um sentido verídico quando é conjunta com um processo de esclarecimento e investigação das violações, publicitando e responsabilizando os agentes envolvidos nos fatos, garantindo atendimento médico e psicológico que propiciem a reabilitação física, social e psíquica. Todavia, se todo esse processo não ocorre de forma conjunta, a reparação econômica pode ser encarada como um modo de 'calar a boca' dos atingidos e das vítimas, produzindo o esquecimento do que foi o terrorismo de Estado e seus efeitos atuais, decretando o silenciamento, como se o possível tivesse sido feito.

Até o momento, as pessoas que tiveram seus direitos violados ao longo da ditadura civil-militar possuem um grande desafio, não ocupar o lugar de vítima, esquecida, mas também não fortalecer o da vítima que tem direito à vingança e se alimenta do ódio reativo, devendo haver um grande cuidado com possíveis modos de espetacularizações da violência sofrida. Coimbra (2010) pontua que o slogan 'transforme sua dor em um instrumento de luta político-social', tem ajudado muito nesse embate, pois, desse modo, há uma afirmação da força que tais sofrimentos trazem. Assim, a publicitação e a disseminação do assunto no espaço público e a coletivização da luta possibilitam que os danos sofridos sejam lembrados e reparados, sem que haja revitimizações.

Tornar pública as experiências, os sofrimentos e as lutas que a história esqueceu e/ou recalcou é fundamental na elaboração dos traumas sociais. A partir dessa perspectiva, acredita-se na importância de todo fenômeno social traumático ser inscrito e elaborado no nível coletivo através da narração, do testemunho e do resgate da memória. Conforme Rosa (2002, p. 47), a oferta de uma forma de escuta "supõe romper barreiras e resgatar a experiência compartilhada com o outro, deve ser uma escuta como testemunho e resgate da memória".

Nessa via, a Comissão teve grande importância, pois sua criação implicou a responsabilização do Estado brasileiro por uma estrutura de violência, perseguição, morte e desaparecimento. Resgatou a memória e história brasileira, reconhecendo a narrativa dos sujeitos que tiveram seus direitos humanos violentados e ressaltou a importância do testemunho como forma de escuta de tais histórias marcadas pelo inaudível. Muitos dados demonstrados pela Comissão já haviam sido apontados por organizações como o Grupo Tortura Nunca Mais; Comissão de mortos e Desaparecidos Políticos; Comissão da Anistia; Brasil Nunca Mais, mas agora ganharam oficialmente o reconhecimento do Estado.

De acordo com os Relatórios da Comissão Nacional da Verdade, foram colhidos 1.121 depoimentos e realizadas 80 audiências e sessões públicas pelo país. A Comissão visitou sete unidades militares e locais utilizados pelas Forças Armadas para a prática de tortura e outras violações. Desse modo, a CNV apontou 377 agentes como responsáveis pelos crimes ocorridos no período ditatorial. Constatou-se que o regime deixou 191 mortos e 243 desaparecidos. Desses últimos, 33 foram identificados ao longo das últimas décadas. A própria Comissão conseguiu identificar os restos mortais de apenas dois 
desaparecidos políticos. Os dados trazidos pela CNV não esgotam a lista de mortos e desaparecidos políticos, já que novas investigações futuras ainda devem ser realizadas (Brasil, 2014a).

O regime ditatorial buscou se eximir da responsabilidade do assassinato de tais presos políticos. Elaboraram versões oficiais falsas para mortes, principalmente quando realizadas sob tortura. Dessa forma, documentos oficiais de morte, certidão de óbito e laudo cadavérico, emitidos pela ditadura, foram somente levados em consideração pela CNV quando os restos mortais foram encontrados ou identificados.

As maiores informações sobre mortos e desaparecidos durante a ditadura vieram da busca incessante dos familiares por informações. A maior parte dos acervos disponíveis foram consultados, além da escuta de ex-presos, sobreviventes de tortura, familiares e agentes da repressão. Porém, apesar do grande esforço a maioria dos casos continuam sem resoluções.

As lacunas dessa história de execuções, tortura e ocultação de cadáveres de opositores políticos à ditadura militar poderiam ser melhor elucidadas hoje caso as Forças Armadas tivessem disponibilizado à CNV os acervos do CIE, CISA e Cenimar, produzidos durante a ditadura, e se, igualmente, tivessem sido prestadas todas as informações requeridas .... As autoridades militares optaram por manter o padrão de resposta negativa ou insuficiente vigente há cinquenta anos, impedindo assim que sejam conhecidas circunstâncias e autores de graves violações de direitos humanos ocorridas durante a ditadura militar (Brasil, 2014c, pp. 35-36).

Diante do trauma social, a política do silenciamento e do esquecimento instaurada no Brasil acaba por perpetuar para além do limite da simbolização a história de uma sociedade. O trauma, enquanto definição do real não simbolizado, produz sintomas de repetição. Assim, quando uma sociedade não consegue elaborar os efeitos desse trauma e busca apagá-lo da memória, o recalque coletivo produz repetições em grandes proporções (Kehl, 2010).

De acordo com Kehl (2012), o Brasil foi o único país da América Latina que obteve um aumento no número de assassinatos cometidos pelas polícias militares após o término da ditadura civil-militar. Desse modo, o mal-dito, criado em torno das violências exercidas no período ditatorial, permite que deixem enormes consequências na nossa sociedade.

Através do terrorismo de Estado que se estabeleceu por meio de violências, torturas e mortes, morreram também ideais, projetos de vida, sonhos e o potencial criativo. Assim, uma geração foi mutilada em sua capacidade de questionar e refletir, restando um legado arbitrário e de impunidade que se perpetua na construção da democracia. Como herança às próximas gerações, restou o medo, o silenciamento e a repetição dos atos violentos.

A violência, quando intraduzível, pode passar a ser transmitida e a se constituir como um fantasma entre o sujeito e seus ascendentes, demarcando uma brecha a ser resolvida e preenchida, ou quem sabe, sanada.

Esses "passados em silêncio", ou "mantidos em segredo", esses "restos insensatos" de um acontecimento inaceitável estão fora de um trabalho psíquico, mas vão obstruir a psique do sujeito e do grupo, permanecendo em estado bruto, consagrados à repetição e oferecidos às identificações da criança, geração sucessora .. .(Baümer, Trahtenberg \& Kahl, 2005, pp. 387-388).

\section{Considerações Finais}

Muitas das violências exercidas no período ditatorial persistiram ao longo dos anos. Torturas, prisões indevidas, mortes e desaparecimentos continuaram a ser presentes. Hoje, o inimigo interno é determinado e julgado conforme o critério dos agentes estatais, sem levar em consideração os direitos dos cidadãos. Anteriormente, os inimigos eram os subversivos e, atualmente, os bandidos. Através das inúmeras formas atuais de asfixia, afogamentos e choques elétricos, as violências foram perpetuadas. Desse modo, o medo continua a ser instaurado enquanto política púbica.

A CNV fez a proposição de algumas recomendações ao Estado Brasileiro referente a formas de reparações e justiça às violações ocorridas na ditadura, mas também às atuais violências exercidas pelo Estado. Estão entre elas: reconhecimento, pelas Forças Armadas, de sua responsabilidade institucional pela ocorrência de graves violações aos direitos humanos; responsabilização jurídica - civil, criminal e administrativa - dos agentes públicos que causaram graves violações, afastandose da interpretação usual referida à anistia; proibição de eventos oficiais que comemorem o golpe militar de 1964; modificação do conteúdo curricular das academias militares e policiais para promoção da democracia e direitos humanos; mecanismos de prevenção e combate à tortura; desvinculação dos institutos médicos legais e dos órgãos de perícia criminal da secretaria de segurança pública e das polícias civis; garantia de atendimento médico e psicossocial às vítimas de graves violações de direitos humanos; desmilitarização das polícias militares estaduais; prosseguimento das atividades voltadas à localização, identificação e entrega aos familiares ou pessoas legitimadas, para sepultamento digno, dos restos mortais dos desaparecidos políticos; preservação da memória e fortalecimento da política de localização e abertura dos arquivos da ditadura (Brasil, 2014a). 
Pode-se afirmar que o relatório final da CNV é uma escrita inicial da contra-história da ditadura civil-militar brasileira, apenas um modo inicial de enfrentamento às violações dos direitos realizadas pelo Estado e seus resquícios na construção democrática. Dessa forma, existe a necessidade de continuidade do trabalho e implantação de uma justiça de transição que preze pela memória, justiça e reparação, assim, esclarecendo e analisando os modos como uma sociedade encara seu legado de violência e autoritarismo.

Ressalta-se que as recomendações da Comissão provocaram grandes expectativas de transformação na sociedade brasileira que, até o momento, não foram supridas. Contudo, pode-se afirmar que sua atuação propôs uma retomada do passado e da memória, um passo a mais no fortalecimento da democracia, trabalhando no contra-fluxo do 'cala-se' que, ainda hoje, insiste em gerar mal-estar e repetições em nossa sociedade. Porém, não se deve esquecer, rememorando a letra de Chico Buarque e Gilberto Gil, que existem muitas pessoas que ainda "lançam gritos desumanos como maneira de serem escutadas" e recebem como resposta a perpetuação da violência, inundada pelo campo do traumático e do silenciamento.

\section{Referências}

Adorno, T. W. (1995). Educação e emancipação. Rio de Janeiro: Paz e Terra.

Arantes, M. A. A. C. (2008). Dor e desamparo: filhos e pais, 40 anos depois. Psicol. clin. [online], 20(2), 75-87.

Arantes, M. A. A. C. (2009a). O Comitê Brasileiro pela anistia de São Paulo (CBA/SP): memórias e fragmentos. In R. Haike e K. Silva (Orgs.), A Luta Pela Anistia (pp. 83-89). Editora UNESP: Arquivo Público do Estado de São Paulo: Imprensa Oficial do estado de São Paulo.

Arantes, M. A. A. C. (2009b). Violência, massacre, tortura e desaparecimento forçado. Link

Baümer, A., Trahtenberg, A. R. C., \& Kahl, M. L. F. (2005). Transgeracionalidade: A patologia da transmissão psíquica entre gerações. Revista da Sociedade Brasileira de Psicanálise de Porto Alegre, 7(2), 369-394.

Benjamin, W. (1985a). Experiência e pobreza. In W. Benjamin, Magia e técnica, arte e política: ensaios sobre literatura e história da cultura (pp. 114-119). São Paulo: Brasiliense (Originalmente publicado em 1933).

Benjamin, W. (1985b). O Narrador. Considerações sobre a obra de Nikolai Leskov In W. Benjamin, Magia, técnica, arte e política: ensaios sobre literatura e história da cultura (pp. 197-221). São Paulo: Brasiliense. (Originalmente publicado em 1936)

Benjamin, W. (1985c). Sobre o conceito da história. In W. Benjamin, Magia e técnica, arte e política: ensaios sobre literatura e história da cultura (pp. 222-232). São Paulo: Brasiliense. (Originalmente publicado em 1940).

Benjamin, W. (1987a). Escavando e lembrando. In W. Benjamin, Rua de Mão única. (pp. 239-240) São Paulo: Brasiliense. (Originalmente publicado em 1932).

Benjamin, W. (1987b). Imagens do Pensamento. In W. Benjamin, Rua de Mão Única. (pp. 143-277). São Paulo: Brasiliense.

Blanchot, M. (1987). O espaço literário. Rio de Janeiro: Rocco.

Bloch, E. (2005). O princípio esperança (Vol. 1). Rio de Janeiro: EdUERJ: Contraponto.

Brasil. Comissão Nacional da Verdade. (2014a). Relatório (Vol. 1). Brasília: CNV. Link

Brasil. Comissão Nacional da Verdade. (2014b). Relatório: textos temáticos (Vol. 2). Brasília: CNV.

Brasil. Comissão Nacional da Verdade. (2014c). Relatório: Mortos e desaparecidos políticos. (Vol. 3). Brasília: CNV.

Buarque, C. (1978). Chico Buarque [LP]. Polygram/Philips: Rio de Janeiro. 
Calirman, C. (2013). Arte brasileira na ditadura militar: Antonio Manuel, Artur Barrio e Cildo Meireles. Rio de Janeiro: Reptil.

Carvalhal, A. P. (2014). Observatório Constitucional: Corte Interamerica decide pela vinculação de sua jurisprudência. Link

Coimbra, C. (2010). Direitos Humanos, terrorismo de Estado, reparações. Correio da APPOA, 196, 21-29.

Conselho Regional de Psicologia da $6^{\mathrm{a}}$ Região (Org.). (2012). Psicologia e o Direito à Memória e à Verdade. São Paulo: CRPSP.

Costa, A. (2011). Rupturas na transmissão. Trivium, 3, 26-33.

Cunha, L. C. (2014). Por que os generais não imitam a Rede Globo. Link

Didi-Huberman, G. (2013). Cascas. Revista Serrote, 13, 99-133.

Endo, P. (2005). A Violência no Coração da Cidade: Um Estudo Psicanalítico. São Paulo: Escuta/Fapesp.

Endo, P. (2011). Um futuro sem origem: transmissão, autoridade e violência. In Associação Psicanalítica de Porto Alegre (Org.), Autoridade e violência (pp. 68-84). Porto Alegre: APPOA.

Ferreira, A. B. H. (2010). Dicionário Aurélio da Língua Portuguesa. 5. ed. Curitiba: Positivo.

Gagnebin, J. M. (2000). Palavras para Hurbinek. In A. Nestrovsky e M. Seligmann-Silva (Orgs.), Catástrofe e representação (pp. 73-98). São Paulo: Escuta.

Gagnebin, J. M. (2006). Lembrar escrever esquecer. São Paulo: Ed. 34.

Jameson, F. (1997). As sementes do tempo. São Paulo: Ática.

Kehl, M. R. (2010). Tortura e sintoma social. In E. Teles \& V. Safatle (orgs.), O que resta da ditadura (pp.123-132). Editora: Boitempo, São Paulo.

Kehl, M. R. (2011). Mulher ou militante. Carta Capital, 660, 84-87.

Kehl, M. R. (2012). O veredicto de Geraldo Alckiman: o governador de SP usa a mesma retórica dos matadores da ditadura. Link

Lacan, J. (2008). O Seminário, livro 16: De um Outro ao outro (1968-69). Rio de Janeiro: Jorge Zahar.

Levi, P. (1988). É isto um homem? Rio de Janeiro: Rocco.

Lisboa, S. (2004). Seria chover no molhado, se o molhado não fosse sangue. In O. Biz (Org.), Sessenta e quatro: para não esquecer (pp. 159-163). Porto Alegre: Literalis.

Moylan, T., \& Baccolini, R. (Orgs). (2007). Utopia Method Vision: The Use Value of Social Dreaming. Bern: Peter Lang.

Oropeza, I. (2012). Memória e direitos humanos: algumas considerações acerca das experiências das Comissões da Verdade. In Conselho Regional De Psicologia Da $6^{\mathrm{a}}$ Região (Org). Psicologia e o Direito à Memória e à Verdade (pp. 15-22). São Paulo: CRPSP.

Portal do Planalto. (2012). Discurso da Presidenta da República, Dilma Rousseff, na cerimônia de instalação da Comissão da Verdade. Link

Rosa, M. D. (2002). Uma escuta psicanalítica das vidas secas. Textura (São Paulo), 2(2), 42-47. 
Safatle, V., \& Teles, E. (Orgs.). (2010). O que resta da ditadura: a exceção brasileira. São Paulo: Boitempo.

Soler, C. (2004). Trauma e fantasia. Stylus: Revista de Psicanálise, 9, 45-59.

Sousa, E., \& Tessler, E. (2004). Violência sem disfarce. Correio da Associação Psicanalítica de Porto Alegre, 126, 5-10.

Sousa, E. (2007). Uma invenção da utopia. São Paulo: Lumme Editora.

Sousa, E. (2010). Caixa-Preta. Correio da APPOA, 196, 21-29.

Tavares, F. (2005). Memórias do Esquecimento: os segredos dos porões da ditadura. Rio de Janeiro: Editora Record.

Ventura, Z. (1988). 1968: o ano que não terminou. Rio de Janeiro: Nova Fronteira.

\section{Endereço para correspondência}

Gabriela Weber Itaquy

Email: gabi.itaquy@hotmail.com

Edson Luiz André de Sousa

Email: edsonlasousa@uol.com.br

Recebido em: 25/04/2017

Revisado em: 05/01/2018

Aceito em: 15/01/2018 